\title{
11. SECONDARILY MODIFIED SEDIMENTS OF THE EASTERN PACIFIC: MAJOR-ELEMENT CHEMISTRY OF SITES 420, 424, AND 425, DEEP SEA DRILLING PROJECT LEG 54
}

\author{
Thomas W. Donnelly, Department of Geological Sciences, State University of New York, Binghamton, New York
}

\section{INTRODUCTION}

Drilling on Leg 54 of the Deep Sea Drilling Project included the recovery of an almost complete sediment section spanning nearly 2.4 m.y. in the Siqueiros fracture zone (Site 420), and two younger sites in the Galapagos fracture zone (Sites 424 and 425 ) representing different degrees of secondary metal enrichment (Figure 1). Samples from these sites were analyzed for major oxides, and the results appear to be highly significant for the general study of secondary metal enrichment in pelagic sediments. Thus, $\mathrm{Fe}, \mathrm{Mn}$, and $\mathrm{P}$ were enriched at all sites, as is nearly universally the case for sedimentary sections penetrating to oceanic crust (Boström and Peterson, 1966; Donnelly, in press), and $\mathrm{Mg}$ and $\mathrm{Na}$ were enriched at Site 420 apparently related to the availability of radiolarian and diatomaceous opal (Donnelly and Merrill, 1977). Two other enrichments found here have not been widely discussed in the sedimentary literature: $\mathrm{K}$ was seen to be enriched in the upper part of Site 420 , apparently as a further manifestation of opaline surface adsorption of metal ions; and silica is enriched at Site 424, apparently as part of the basal iron-manganese enrichment stage.

\section{METHODS}

A suite of samples, intended to be representative of the intervals sampled and not to include exceptional features, was collected by the DSDP curatorial staff. These samples were analyzed by methods long in use in our laboratory (Donnelly and Wallace, 1976a and b), except that they were pre-washed once in deionized water. Past experience has shown that highly opaline sediments from the eastern Pacific have such a high porosity that our customary correction for pore-water sodium, magnesium, calcium, and potassium (through analysis of water-soluble chloride) may amount to very nearly 100 per cent of analyzed sodium in an unwashed sample, and more than half the magnesium. The samples received in our laboratory were exceptionally moist and soft, and all were washed by centrifuging in deionized water. A small amount of original sea water remained and was corrected for in the usual way, using a separate determination of water-soluble chloride, the shipboard determinations of $\mathrm{Ca}, \mathrm{Mg}$, and $\mathrm{Cl}$ in the pore water, and sea-water ratios of $\mathrm{Na} / \mathrm{Cl}$ and $\mathrm{K} / \mathrm{Cl}$. At the time of washing, several samples were sieved ( 325 mesh) and the coarse fragment's analyzed separately. (The results are published in tabulated form in the Appendix to this volume.) The analyses show that there is relatively little difference between the coarse and fine fractions, except that the former are commonly more enriched in the metal-rich, secondarily added material characteristic of these sediments.

One analytical problem not encountered before was the determination of very small amounts of aluminum in the presence of very large amounts of iron and magnesium, using the calcium alizarin colorimetric method. We analyzed several of these samples three times, with erratic results, and I feel that the aluminum determinations might be in error by larger amounts than usual. Normally we find that $\mathrm{Al}_{2} \mathrm{O}_{3}$ is determined to better than 0.2 per cent precision in the average clay; some of these samples with very high $\mathrm{Fe} / \mathrm{Al}$ or $\mathrm{Mn} / \mathrm{Al}$ ratios might have errors as large as 0.4 per cent.

Separate ferric and ferrous determinations were made for several samples (Table 1). The method, which is in wide use, involves digesting the sample in a mixture of $\mathrm{HF}$ and $\mathrm{H}_{2} \mathrm{SO}_{4}$, and titrating with potassium dichromate, using sodium diphenylamine sulfonate as an indicator. The results show that virtually all of the iron occurs in the ferric form.

Cumulative accumulations were calculated, using the shipboard biostratigraphy and available sediment density-porosity measurements (GRAPE), according to the method of Donnelly and Merrill (1977). However, these calculations are probably much less accurate than other oceanic sediment calculations: the biostratigraphy is relatively imprecise for these very young sediment sections, and the porosities are very high in these samples, leading to large probable errors in the calculated solid density of the sediments.

An estimate was made of the total excessive accumulation of several chemical species (Table 2) at Sites 420, 424 , and 425 , and compared with excess accumulations of these species at other eastern Pacific sites. The excess accumulation was calculated on the basis of a "base ratio" of the species to aluminum, which is estimated both by noting that the upper parts of some sites appear to have these ratios uniform and low, and by taking these ratios from the upper portions of hemipelagic sites (such as DSDP Sites 34 and 84 ) for which excess oxide accumulations are much less likely. In the case of Pacific sediments, terrigenous contributions are very low, and the assumption of widely differing base ratios for the oxides results in only very minor differences in the estimated excess accumulations.

\section{RESULTS}

\section{Sites $\mathbf{4 2 4}$ and $\mathbf{4 2 5}$}

These sites were drilled $22 \mathrm{~km}$ south and $62 \mathrm{~km}$ north of the Galapagos spreading center, respectively; the first on crust dated approximately at $0.5 \mathrm{~m}$.y., and the sec- 


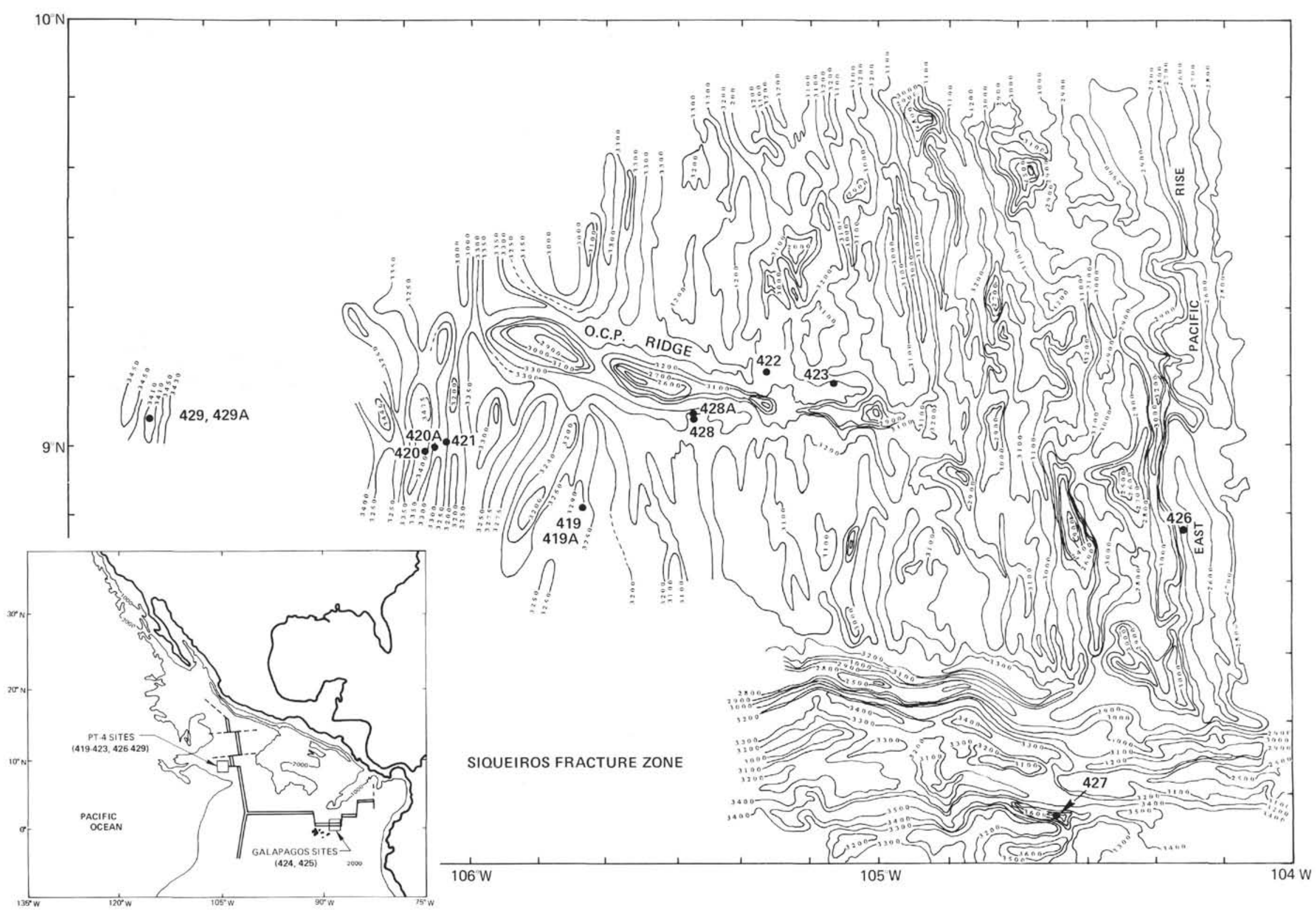

Figure 1. Location of Deep Sea Drilling Project sites for Leg 54. 
TABLE 1

Separate Ferric-Ferrous Determinations, Site 424

\begin{tabular}{|c|c|c|c|c|c|c|c|c|}
\hline $\begin{array}{l}\text { Sample. |Core-Section } \\
\text { Top of Interval (in } \mathrm{cm}) \mid\end{array}$ & $424-2-4,98 \mathrm{C}$ & $424-2-4,98 \mathrm{~F}$ & $424-3-1,34 \mathrm{~F}$ & $424 \mathrm{~A}-2-2,6$ & $424 \mathrm{~B}-2-3,18 \mathrm{C}$ & $424 \mathrm{~B}-2-3,128 \mathrm{C}$ & $424 \mathrm{~B}-3-3,71 \mathrm{C}$ & $424 \mathrm{~B}-3-3,71 \mathrm{~F}$ \\
\hline $\mathrm{Fe}_{2} \mathrm{O}_{3}$ & 28.6 & 27.8 & 27.9 & 27.7 & 28.8 & 26.7 & 27.2 & 27.9 \\
\hline 1eo & 0.89 & 0.91 & 0.28 & 1.36 & 0.92 & 0.64 & 0.69 & 0.76 \\
\hline
\end{tabular}

Note: Samples babeled " $"$ " and " $\% "$ are coarse and fine fractions, respectively, of sieved (325-mesh) sediment.

TABLE 2

Excess Accumulations of Oxides for Eastern Pacific Drilled Sites

\begin{tabular}{|c|c|c|c|c|c|c|c|c|c|c|c|c|c|c|c|c|c|}
\hline \multirow{2}{*}{$\begin{array}{l}\text { DSDP } \\
\text { Site }\end{array}$} & \multirow[b]{2}{*}{ Time } & \multirow[b]{2}{*}{$\mathrm{Si} / \mathrm{Al}$} & \multicolumn{3}{|c|}{$\mathrm{Fe}_{2} \mathrm{O}_{3}$} & \multicolumn{3}{|c|}{$\mathrm{MnO}$} & \multicolumn{3}{|c|}{$\mathrm{MgO}^{*}$} & \multicolumn{3}{|c|}{$\mathrm{K}_{2} \mathrm{O}$} & \multicolumn{3}{|c|}{$\mathrm{P}_{2} \mathrm{O}_{5}$} \\
\hline & & & Base & Amount & $\%$ & Base & Amount & $\%$ & Base & Amount & $\%$ & Base & Amount & $\%$ & Base & Amount & $\%$ \\
\hline 37 & 25 & 3.11 & 0.30 & 195 & 74 & 0.012 & 48 & 87 & - & - & - & 0.175 & 6 & 20 & 0.008 & 6 & 79 \\
\hline 42 & 22 & 15.0 & 0.30 & 92 & 58 & 0.012 & 24 & 93 & 0.30 & 26 & 44 & 0.175 & 7.5 & 25 & 0.008 & 17 & 92 \\
\hline 70 & 18 & 11.8 & 0.30 & 113 & 44 & 0.012 & 42 & 90 & - & - & - & 0.175 & 14.4 & 23 & 0.008 & 40 & 92 \\
\hline 73 & $45^{*}$ & 14.4 & 0.30 & 102 & 59 & 0.012 & 26 & 90 & - & - & - & 0.175 & 19 & 45 & 0.008 & 49 & 98 \\
\hline 83 & $12 *$ & 8.10 & 0.30 & 192 & 70 & 0.012 & 47 & 93 & 0.30 & 98 & 70 & - & - & - & 0.008 & 15 & 87 \\
\hline 159 & $23^{*}$ & 3.91 & 0.30 & 262 & 62 & 0.012 & 72 & 92 & 0.30 & 38 & 32 & 0.175 & 23.5 & 66 & 0.008 & 13 & 77 \\
\hline 319 & $15^{*}$ & 5.45 & 0.30 & 423 & 93 & 0.012 & 101 & 98 & 0.30 & 25 & 61 & 0.175 & 4.8 & 30 & 0.008 & 27 & 99 \\
\hline 321 & 33 & 3.50 & 0.30 & 158 & 59 & 0.012 & 60 & 94 & - & - & - & 0.175 & 11.4 & 24 & 0.008 & 25 & 91 \\
\hline 420 & $2.4^{*}$ & 5.38 & 0.30 & 282 & 70 & 0.012 & 45 & 91 & 0.30 & 52 & 45 & 0.175 & 16 & 27 & 0.008 & 14 & 84 \\
\hline 424 & $0.5^{*}$ & 13.8 & 0.30 & 233 & 94 & 0.012 & 11 & 98 & 0.30 & 37 & 83 & 0.175 & 22 & 81 & 0.008 & 2 & 96 \\
\hline 425 & $1.8^{*}$ & 5.71 & 0.30 & 18 & 34 & 0.012 & 4 & 75 & 0.30 & 8 & 32 & - & - & - & 0.008 & 3 & 88 \\
\hline
\end{tabular}

Note: "Time" is millions of years above base that iron enrichment can be detected (an asterisk indicates that the uppermost sediments are enriched, and that enrichment may be continuing); $\mathrm{Si} / \mathrm{Al}$ refers to the atomic ratio of $\mathrm{Si}$ and $\mathrm{Al}$ in the enriched interval; "Base" is the value for each oxide of the atomic ratio of the element to Al used to establish the terrigenous contribution; "Amount" is total $\mathrm{g} / \mathrm{cm} 2 \mathrm{for}$ the enriched interval, and "\%" is the percentage of the oxide in that interval that can be referred to the category of enriched (values omitted where percentage is less than 20). $\mathrm{MgO} *$ refers to $\mathrm{MgO}$ from which has been subtracted the $\mathrm{Mg}$ referred to the original carbonate phase (assuming an atomic ratio $\mathrm{Ca} / \mathrm{Mg}=200$ ).

ond on crust about 1.8 m.y. old. In gross appearance, the sediment at Site 424 (only Holes 424, 424A, and 424B were studied here) is divisible into two lithologies: a pale colored calcareous ooze (a more siliceous ooze from Hole $424 \mathrm{C}$ was not studied by me) and a deeply colored "hydrothermal deposit." The core recovery for each hole was poor. Although the holes were positioned either on top of mounds (Holes 424 and 424A) or between mounds (Hole 424B), I see no evidence that the sediment sections in these three holes differ laterally. I have therefore chosen to treat the sediments as a composite representing one section, which has abundant hydrothermal material near the top and more ordinary ("unmodified") ooze below.

The sediments from Site 425 resemble chemically the pale-colored oozes from Site 424. In the following treatment, the chemical composition of the Site 425 sediments and the lower, "unmodified" Site 424 sediments are considered to represent the original sedimentary material probably deposited at Site 424 during its entire history of sedimentation, and to which has been added at Site 424 the "hydrothermal" component.

As our analyses show, the sediment at Site 424 contains high values of $\mathrm{Fe}, \mathrm{Mn}, \mathrm{Mg}$, and $\mathrm{K}$, and Si relative to Al. Relative cumulative accumulation rates of these elements (Table 3 ) show that the rates of accumulation of $\mathrm{Al}, \mathrm{Ti}, \mathrm{Ca}$, and $\mathrm{P}$ appear to be comparable for Sites 424 and $425-$ a similarity that could be highly fortui-

\footnotetext{
' Shipboard lithological terminology is used in this discussion.
}

tous because of the poor biostratigraphic control and the low sediment densities. Of the remaining elements, $\mathrm{Na}$ is sufficiently close that sampling might be responsible for the observed differences. However, $\mathrm{Si}, \mathrm{Mg}$, $\mathrm{Mn}, \mathrm{K}$, and $\mathrm{Fe}$ appear to have accumulated at much higher rates at Site 424 than at Site 425 . A part of this accumulation is authigenic at this and several other Pacific sites (Table 3). This excess is discernible in many cases only through chemical analysis and could be termed cryptic. An alternative explanation for the chemical relationships would be that they represent an ordinary sediment from which certain components have been subtracted to yield an unusual residuum. This hypothesis is rejected on two grounds: (1) the subtracted elements would have to be $\mathrm{Al}, \mathrm{Ti}$, and $\mathrm{Ca}$, two of which

TABLE 3

\begin{tabular}{|c|c|c|c|}
\hline \multicolumn{4}{|c|}{$\begin{array}{c}\text { Ratio of Calculated Rates of Ac- } \\
\text { cumulation of Oxides at Site } 424 \\
\text { relative to Site } 425 \text {, Assuming } \\
\text { Total Ages of } 0.5 \text { and } 1.8 \\
\text { m.y., respectively }\end{array}$} \\
\hline $\mathrm{SiO}_{2}$ & 3.7 & $\mathrm{MgO}^{*}$ & 5.9 \\
\hline $\mathrm{TiO}_{2}$ & 2.2 & $\mathrm{CaO}$ & 1.7 \\
\hline $\mathrm{Al}_{2} \mathrm{O}_{3}$ & 1.5 & $\mathrm{Na}_{2} \mathrm{O}$ & 2.6 \\
\hline $\mathrm{Fe}_{2} \mathrm{O}_{3}$ & 16.7 & $\mathrm{~K}_{2} \mathrm{O}$ & 9.2 \\
\hline $\mathrm{MnO}$ & 7.6 & $\mathrm{P}_{2} \mathrm{O}_{5}$ & 2.2 \\
\hline
\end{tabular}


are highly insoluble in natural waters of widely ranging chemical character, and (2) the estimated accumulation rates of these elements, though crude, are comparable at Sites 424 and 425 .

Manganese is, in toto, greatly enriched. However, its distribution from sample to sample is highly erratic, and inspection of the data in Table 1 reveals that this metal is not related to the occurrence of any other element in a coherent fashion. Apparently manganese, at this site, has either behaved from the start as a completely independent chemical variable, or it has been secondarily redistributed within the sediment section following deposition. The data from these sites do not allow an evaluation of these alternatives, but unpublished data from other sites, as well as some information on the coherence among $\mathrm{Fe}, \mathrm{Mg}, \mathrm{Mn}$, and $\mathrm{Si}$ from DSDP Site 42 (Donnelly and Merrill, 1977) shows that in some cases, manganese shows a very coherent behavior with the other enriched elements.

Enrichment in silica in the hydrothermal deposits from Site 424 is not paralleled at other sites, at which high basal silica values, and high $\mathrm{Si} / \mathrm{Al}$ ratios (such as Site 42, Donnelly and Merrill, 1977) can be associated with abundant radiolarians. In the present case, the highest $\mathrm{Si} / \mathrm{Al}$ ratios at Site 424 occur in sediment with no recognizable opaline fossils, and the coherence between $\mathrm{Si} / \mathrm{Al}$ on the one hand and the $\mathrm{Fe} / \mathrm{Al}, \mathrm{Mg} / \mathrm{Al}$, and $\mathrm{K} / \mathrm{Al}$ ratios on the other hand suggest that silica enrichment in this case might not be biogenic.

The hydrothermal deposits of Site 424 have notably high iron contents; and a highly coherent relationship exists between $\mathrm{Si}$ and $\mathrm{Fe}$, seen as the $\mathrm{Si} / \mathrm{Al}$ and $\mathrm{Fe} / \mathrm{Al}$ ratios. Table 4 summarizes the regressions between these ratios, as well as others. The regressions do not trend through the origin, but appear to represent additions of a component to a little modified ooze, such as is seen in the lower part of Site 424 or at Site 425 (Figure 2). The "unmodified"' ooze samples of lower Site 424 appear in Figure 2 as points relatively close to the origin. They tend to a mild increase in $\mathrm{Fe} / \mathrm{Al}$ with no increase in $\mathrm{Si} / \mathrm{Al}$, which represents the more general case of basal iron enrichment. The upper hydrothermal samples follow a very well defined regression trend, whose $\mathrm{Si} / \mathrm{Fe}$ atomic ratio is 2.27 .

The behavior of magnesium in upper Site 424 parallels that of iron. The sum of iron and magnesium has even a slightly better correlation coefficient than either element alone (Figure 3, Table 4), and the $\mathrm{Si} / \mathrm{Mg}$ ratio is 8.55 .

Potassium and silicon have a similar coherence (Table 4, Figure 4), with a $\mathrm{Si} / \mathrm{K}$ ratio of 12.0 . Finally,

TABLE 4

Regressions for Oxide/Aluminum Ratios for all samples, Site 424

\begin{tabular}{ll}
$\mathrm{Fe} / \mathrm{Al}=0.441 \mathrm{Si} / \mathrm{Al}-1.027$ & $r=0.990$ \\
$\mathrm{Mg} / \mathrm{Al} l^{*}=0.117 \mathrm{Si} / \mathrm{Al}+0.209$ & $r=0.982$ \\
$(\mathrm{Fe}+\mathrm{Mg}) / \mathrm{Al}=0.56 \mathrm{Si} / \mathrm{Al}-0.82$ & $r=0.993$ \\
$\mathrm{~K} / \mathrm{Al}=0.083 \mathrm{Si} / \mathrm{Al}-0.297$ & $r=0.983$ \\
\hline
\end{tabular}

Note: $\mathrm{Mg} / \mathrm{Al}^{*}$ refers to the $\mathrm{Mg}$ corrected for the carbonate $\mathrm{Mg}$, as in Table 3 .

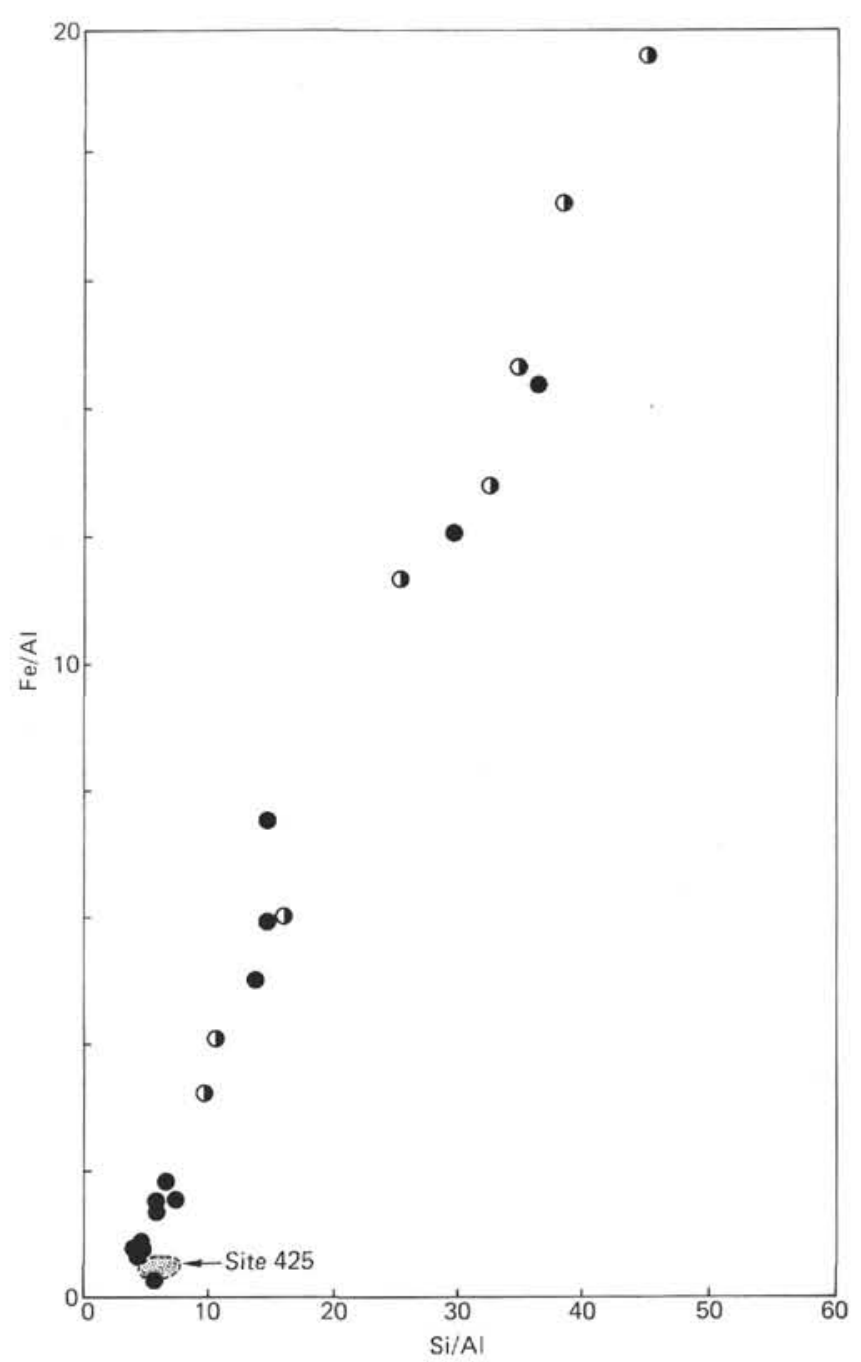

Figure 2. Diagram showing atomic ratios $\mathrm{Fe} / \mathrm{Al}$ versus Si/Al of Site 424 and 425 sediments. Half-filled circles represent coarse fractions from Site 424 . Site 425 sediments cluster tightly near the origin, in stippled field.

$\mathrm{K} / \mathrm{Al}$ and the ratio $(\mathrm{Fe}+\mathrm{Mg}) / \mathrm{Al}$ are coherent (Figure 5), except some of the mildly enriched lower Site 424 ooze samples appear to show enrichment in $(\mathrm{Fe}+\mathrm{Mg}) / \mathrm{Al}$ but not $\mathrm{K} / \mathrm{Al}$, which situation is very widespread among Pacific sites (mainly unpublished data).

The coherence among the four principal enriched major oxides suggests that a component of relatively uniform composition has been added in variable amounts to an ooze which also has a small amount of iron hydrate enrichment. The uniformity of the component and the values of the elemental ratios suggest that it is a silicate mineral in which aluminum is a very minor or accidental constituent.

There are two ways of calculating the composition of the phase. The first is to compute a hypothetical aluminum-free mineral with $\mathrm{Si}, \mathrm{Fe}, \mathrm{Mg}$, and $\mathrm{K}$, assuming all the iron is ferric (Table 1), and assuming that this phase is responsible for the compositional variations shown in Figures 2, 3, 4, and 5, and in Table 4. This mineral is calculated with 22 oxygens and is assumed to 


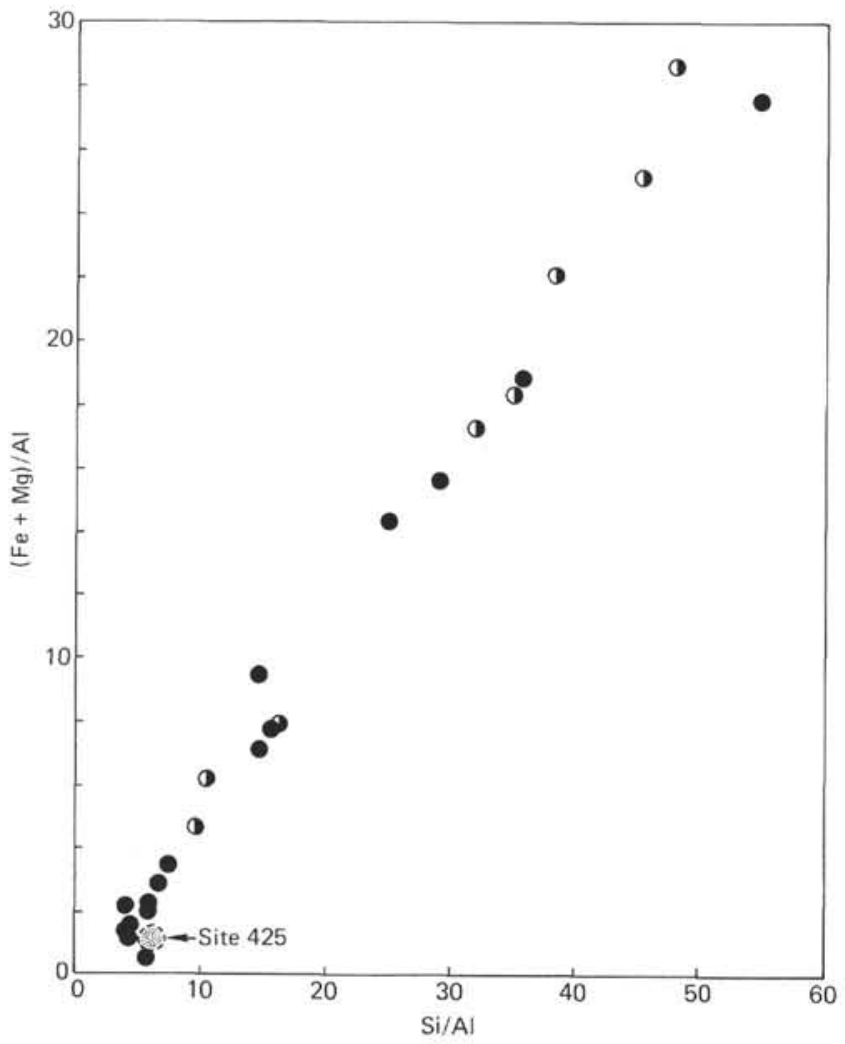

Figure 3. Diagram showing atomic ratios $(\mathrm{Fe}+\mathrm{Mg}) / \mathrm{Al}$ versus Si/Al for Sites 424 and 425. Explanation as for Figure 2.

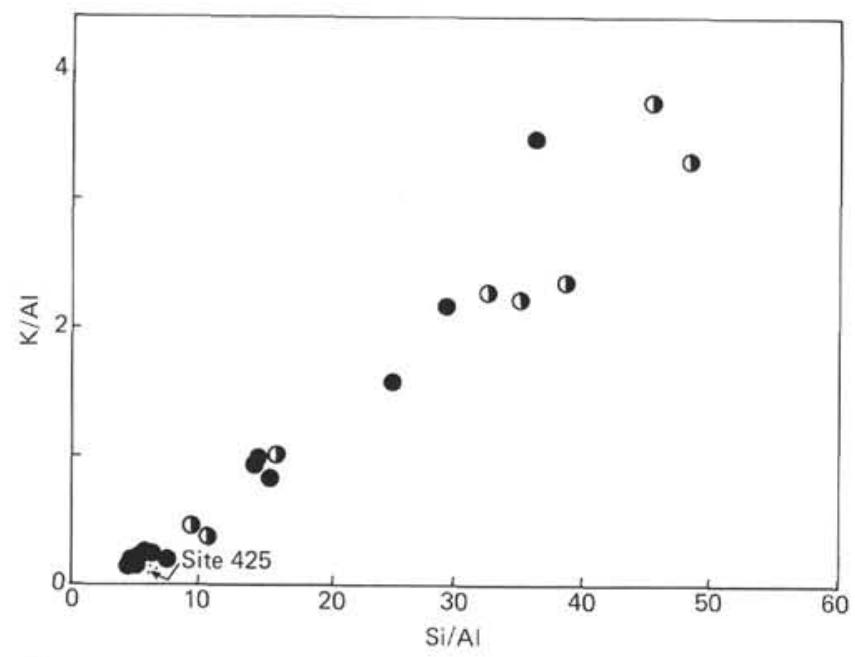

Figure 4. Diagram showing atomic ratios $K / A l$ versus $\mathrm{Si} / \mathrm{Al}$ for Sites 424 and 425 . Explanation as for Figure 2.

be a phyllosilicate. The calculated formula (Table 5) is $\left(\mathrm{K}_{0.71}\right)\left(\mathrm{Fe}_{2.86}^{+3} \mathrm{Mg}_{1.38}\right)\left(\mathrm{Si}_{7.94} \mathrm{Fe}_{0.06}^{+3}\right) \mathrm{O}_{20}(\mathrm{OH})_{4}$. The second method is to note that six of the analyses are apparently close to the end-member composition, based on low values of $\mathrm{Mn}, \mathrm{Ca}$, and $\mathrm{Ti}$. These are recalculated (Table 5), allotting $\mathrm{Na}$ and $\mathrm{Ca}$ to the interlayer position and putting the small amount of $\mathrm{Al}$ preferentially into the tetrahedral position. Averaging these six recalculated compositions results in both $\mathrm{Al}$ and $\mathrm{Fe}^{+3}$ in the tetrahe-

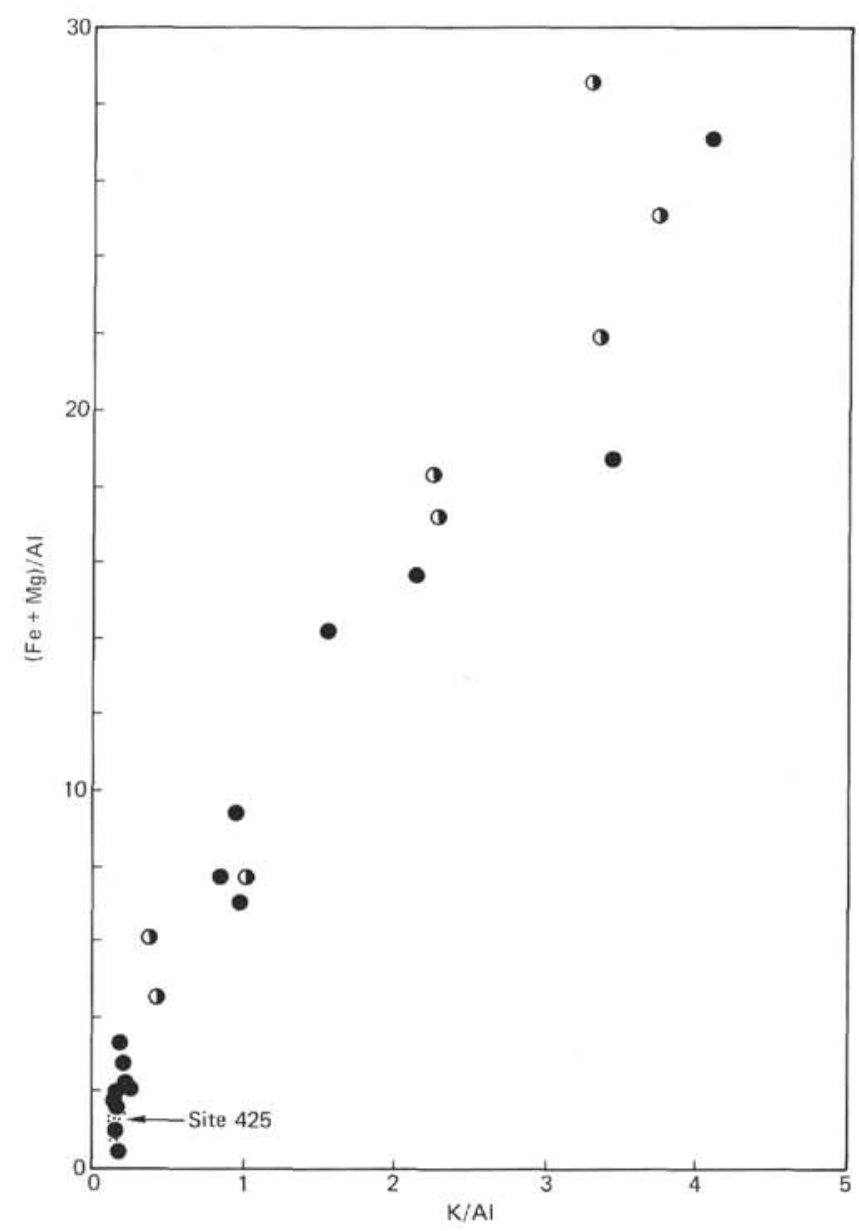

Figure 5. Diagram showing atomic ratios $(\mathrm{Fe}+$ $M g$ ) $/ A l$ versus $K / A l$ for Sites 424 and 425 . Explanation as for Figure 2.

dral and octahedral positions. The average formula is $\left(\mathrm{K}_{0.53} \mathrm{Na}_{0.18} \mathrm{Ca}_{0.21}\right)\left(\mathrm{Fe}_{3.01}^{+} \mathrm{Mg}_{0.92} \mathrm{Al}_{0.08}\right)\left(\mathrm{Si}_{7.71} \mathrm{Al}_{0.22} \mathrm{Fe}_{0.07}^{+3}\right)$ $\mathrm{O}_{20}(\mathrm{OH})_{4}$, which is close to the first calculation. These formulae suggest an interlayered celadonite-nontronite, with considerable magnesium. Note that the octahedral occupancy averages 4.01 , which is dioctahedral. Two specimens with some Mn (Sample 424B-3-3, 71-73 cm C and F) yield octahedral occupancies of 4.20 and 4.10 when recalculated, suggesting that $\mathrm{Mn}$ is not part of this mineral. The variability of $\mathrm{Mn}$ also suggests that this is present as a discrete phase.

Smear slide examination of the most enriched samples shows that the latter consist almost entirely of a bright green, extremely fine grained, highly birefringent pelletoidal substance. X-ray diffraction of four samples, one of which is shown in Figure 6, shows that the mineral has a characteristic (001) peak which has an angular position between that of mica and smectite, a very weak (002) and a strong (003) diffraction. Treatment with ethylene glycol splits these peaks, causing the basal peak to split into a broad but well-defined $10 \AA$ mica peak with a poorly defined $17 \AA$ shoulder. This pattern is characteristic of an interlayered mica-smectite mineral. Glycolation shifts the (003) peak slightly and causes the (002) peak to split into two nearly unrecog- 
TABLE 5

Recalculated Formulae of Hypothetical End Member Celadonite-Nontronite

\begin{tabular}{|c|c|c|c|c|c|c|c|c|c|}
\hline & & \multirow{2}{*}{$\begin{array}{l}\text { Hypothetical; } \\
\text { Based on Slopes } \\
\text { of Table } 4\end{array}$} & \multicolumn{6}{|c|}{$\begin{array}{c}\text { Sample } \\
{[\text { Core-Section }- \text { Top of Interval }(\text { in } \mathrm{cm})]}\end{array}$} & \multirow[b]{2}{*}{ Average } \\
\hline & & & $\begin{array}{l}424 \mathrm{~B}-2- \\
3,18 \mathrm{C}\end{array}$ & $\begin{array}{l}424 \mathrm{~B}-2- \\
3,18 \mathrm{~F}\end{array}$ & $\begin{array}{l}424 \mathrm{~B}-2- \\
3,128 \mathrm{C}\end{array}$ & $\begin{array}{l}424-2- \\
4,98 \mathrm{C}\end{array}$ & $\begin{array}{c}424 \mathrm{~B}-3- \\
3,71 \mathrm{C}\end{array}$ & $\begin{array}{l}424 \mathrm{~B}-3- \\
3,71 \mathrm{~F}\end{array}$ & \\
\hline Tetrahedral & $\begin{array}{l}\mathrm{Si} \\
\mathrm{Al} \\
\mathrm{Fe}^{+3}\end{array}$ & 0.20 & $\begin{array}{l}7.80 \\
0.20 \\
-\end{array}$ & $\begin{array}{l}7.80 \\
0.20 \\
-\end{array}$ & $\begin{array}{l}7.67 \\
0.33 \\
-\end{array}$ & $\begin{array}{l}7.59 \\
0.19 \\
0.22\end{array}$ & $\begin{array}{l}7.59 \\
0.24 \\
0.17\end{array}$ & $\begin{array}{l}7.81 \\
0.15 \\
0.04\end{array}$ & $\begin{array}{l}7.71 \\
0.22 \\
0.07\end{array}$ \\
\hline Octahedral & $\begin{array}{l}\mathrm{Al} \\
\mathrm{Fe}^{+3} \\
\mathrm{Mg}\end{array}$ & $\begin{array}{l}3.24 \\
0.91\end{array}$ & $\begin{array}{l}0.02 \\
3.20 \\
0.82\end{array}$ & $\begin{array}{l}0.30 \\
2.96 \\
0.85\end{array}$ & $\begin{array}{l}0.15 \\
2.92 \\
0.87\end{array}$ & $\begin{array}{l}3 . \overline{10} \\
0.93\end{array}$ & $\begin{array}{l}-\overline{89} \\
1.04\end{array}$ & $\begin{array}{l}\overline{-} .99 \\
0.99\end{array}$ & $\begin{array}{l}0.08 \\
3.01 \\
0.92\end{array}$ \\
\hline Total & & 4.15 & 4.04 & 4.11 & 3.94 & 4.03 & 3.93 & 3.98 & 4.01 \\
\hline Interlayer & $\begin{array}{l}\mathrm{Ca} \\
\mathrm{Na} \\
\mathrm{K}\end{array}$ & 0.65 & $\begin{array}{l}0.06 \\
0.26 \\
0.50\end{array}$ & $\begin{array}{l}0.15 \\
0.05 \\
0.41\end{array}$ & $\begin{array}{l}0.17 \\
0.18 \\
0.49\end{array}$ & $\begin{array}{l}0.17 \\
0.23 \\
0.66\end{array}$ & $\begin{array}{l}0.44 \\
0.22 \\
0.54\end{array}$ & $\begin{array}{l}0.25 \\
0.13 \\
0.58\end{array}$ & $\begin{array}{l}0.21 \\
0.18 \\
0.53\end{array}$ \\
\hline
\end{tabular}

Note: For explanation of "C" and "F", see Table 1.

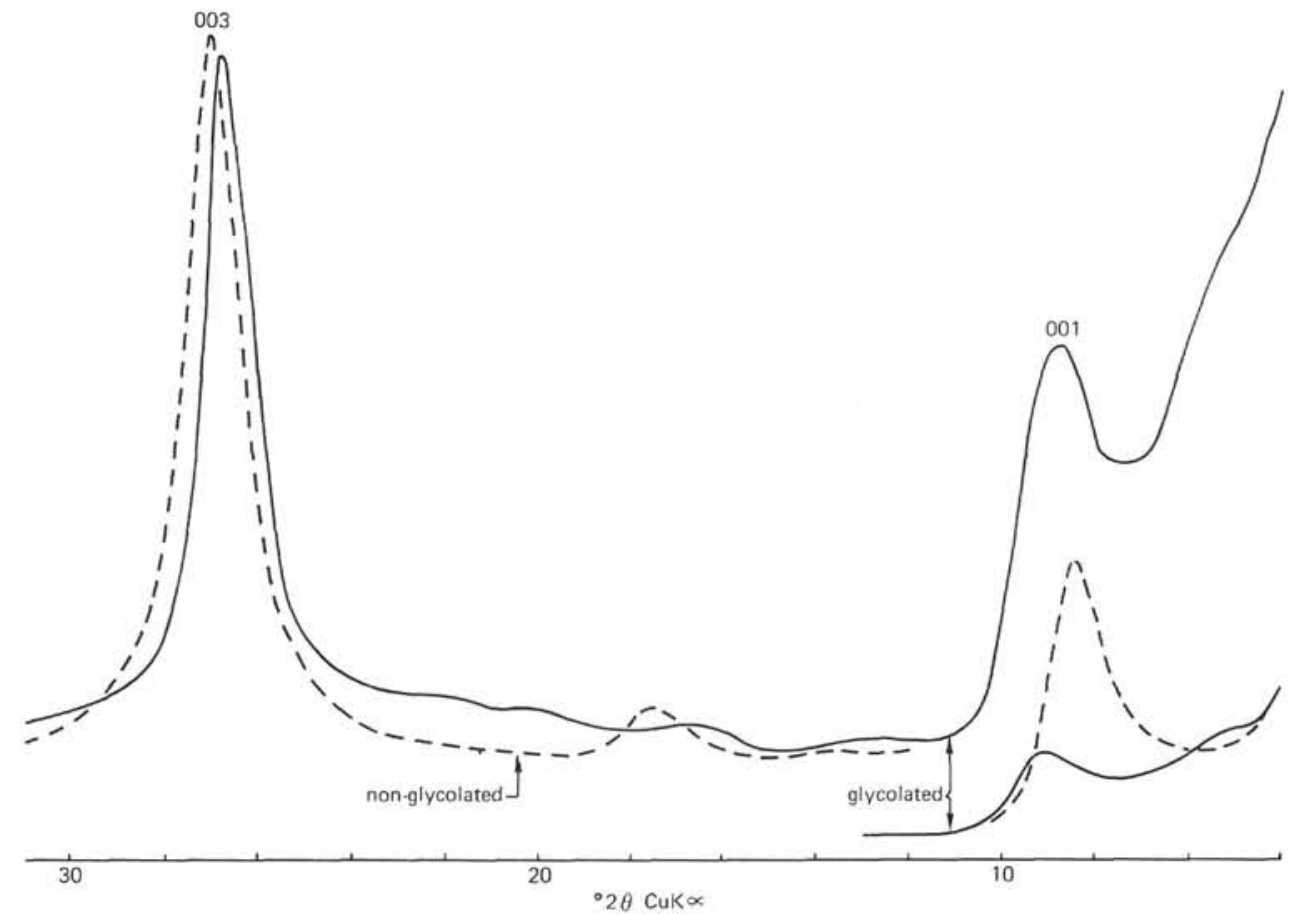

Figure 6. X-ray diffractometer trace for unglycolated (dashed lines) and glycolated

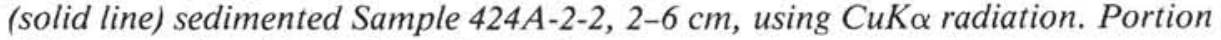
at lower angles shown at smaller scale.

nizable tiny peaks. Equally characteristic of its interlayered condition is the disparity between the basal spacing of the mica component calculated separately from the positions of the $(003)$ and $(001)$ peaks, including the appropriate corrections for the diffractometer geometry. The X-ray characteristics and inferred chemical composition based on trends among bulk samples agree in assigning the character of the hydrothermal deposits largely to an addition of a discrete, compositionally uniform phase over an unknown period represented by more than 10 meters of sediment. The formation of this hypothetical phase is beyond the scope of this paper, largely because unpublished data from other drilled sites add a variety of important observations.
However, the minimal conditions must be that two substances only slightly soluble in sea water (silica and iron) combine close to a hydrothermal vent to form a stochiometric complex.

The further association with magnesium and potassium to yield a properly crystalline, and compositionally uniform, substance requires no special source for these two ions. Evidence from other sites suggests that potassium association is distinctly later than the $\mathrm{Fe}-\mathrm{Mg}-\mathrm{Si}$ association, and may be absent in some cases. Thus, the primary mineral appears to be a smectite, and this may or may not be modified by absorption of potassium to form the interlayer mineral seen at Site 424 . Which of the two hydrothermal substances is initially accumu- 
lated in excess of the stochiometric ratio and the fate of this excess are both unknown, but the observations demand that the sedimentary material at the site have retained none of this excess. Thus, some sort of hydraulic differentiation causes the smectite or smectite-mica pellets to settle out close to the vent, and excess iron hydroxide, amorphous silica, or perhaps both, to move away from the site. As mentioned above, although manganese is also excessive here, its relationships are totally incoherent with the other elements, and it is not known whether the excess manganese was always in a discrete phase or whether the original smectite-mica interlayer phase contained manganese which then was redistributed secondarily.

An alternative suggestion is that the modifying substances might have been derived from beneath the site and moved upward through the sediment. This hypothesis is attractive because it suggests the possibility that the fluid was reducing and capable of transporting large quantities of iron. However, the coherence among the additions of the four elements $\mathrm{Si}, \mathrm{Fe}, \mathrm{Mg}$, and $\mathrm{K}$ would require either that they were introduced in a fortuitous ratio, or that three excessive elements were expelled completely from the surface of the sediment, or that some more complicated scheme was involved. The fact that the lower sediments would then have almost completely escaped this addition might be explained on the basis of oxidizing conditions near the sediment/seawater interface, but the hydrothermal substance occurs over an interval of at least 10 meters and is apparently interlayered with little modified ooze, favoring a sedimentation hypothesis. An additional problem with introduction from below is common to many Pacific sites: the basalt under the sediment is very fresh and shows little chemical evidence of alteration, based on shipboard loss-on-ignition and potassium determinations.

In summary, the phenomenon of $\mathrm{Si}-\mathrm{Fe}-\mathrm{Mg}-\mathrm{K}$ enrichment seen so vividly at Site 424 is mirrored in various ways at several other Pacific sites. The nearby occurrence of sediment free of this substance (Site 425) enables me to confirm the nature of the largely unmodified ooze. Finally, the examples of extreme chemical enrichment seen here permits the estimation that the added substance has the composition of a smectite-mica interlayered phase; the X-ray diffraction characteristics of sediment samples appear to confirm this determination. The origin of this phase-whether in the water column followed by sedimentation or in the sediment by action of hydrothermal fluids-remains a mystery, but several lines of evidence favor the former possibility and require that $\mathrm{Si}$ and $\mathrm{Fe}$ be erupted directly into sea water for an unspecified time.

\section{Site $\mathbf{4 2 0}$}

This site is located about 2400 kilometers northwest of Sites 424 and 425 , and at first glance a consideration of the chemistry of its sediments would appear to bear little relation to those of the latter two sites. However, there are important similarities. All three sites have highly siliceous oozes, and all show some enrichment of iron, magnesium, and potassium, as well as manganese and phosphorus. Although only some of the shallower samples from Site 420 are brownish in color, the chemical character of the entire sediment section shows that iron is enriched, as well as several other elements. There are two important differences between the two groups of sediments: (1) three samples from Site 420 have about 10 per cent volcanic material in smear slide and one has about 20 per cent; these have a distinctive chemistry reflective of the volcanic component, (2) the shallowest samples, representing about the latest $1 \mathrm{~m} . \mathrm{y}$. of sedimentation, show a distinctive chemical trend unrelated to the silica-iron enrichment seen in its various forms at various sites, while deeper samples show some, but not all, of the chemical relationships of this enrichment seen at Site 424.

The shallower samples at Site 420 show a high coherence between $\mathrm{Mg} / \mathrm{Al}$ and $\mathrm{Si} / \mathrm{Al}$ (Figure 7), as shown by Donnelly and Merrill (1977) for DSDP Site 42, as well as the Caribbean DSDP Site 29. The $\mathrm{Si} / \mathrm{Mg}$ value for Site 420 , however, is 10 , which is about half of that for the two Paleogene sites mentioned by these authors. The reason for this disparity is not immediately clear, but, according to their hypothesis of surface adsorption, the surface area of younger opaline debris might be higher than the Paleogene debris of the other two sites. A problem with these samples, however, is that their magnesium enrichment occurs in a section whose sedimentation rate is about 40 meters/m.y.; thus, their diffusion

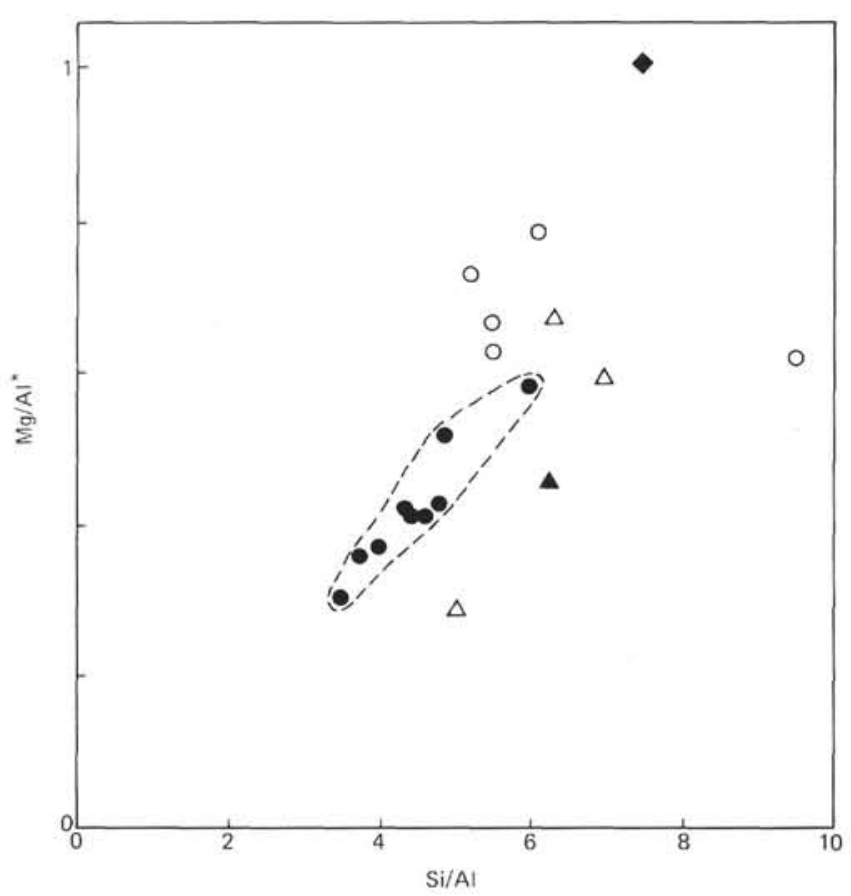

Figure 7. Diagram showing atomic ratios $\mathrm{Mg} / \mathrm{Al}$ * versus Si/Al for sediments from Site 420. Solid circles represent shallower sediments, open circles deeper sediments, open triangles sediments with approximately 10 per cent volcanic material, solid triangle sample with about 20 per cent volcanic debris, and solid diamond, the deepest sample. 
model cannot account for this enrichment. The relationship between $\mathrm{Na} / \mathrm{Al}$ and $\mathrm{Si} / \mathrm{Al}$ seen for virtually all opaline sites (Donnelly and Merrill, 1977) is seen here also, with a $\mathrm{Si} / \mathrm{Na}$ value of about 26 (Figure 8). Potassium and silica are also related, with a $\mathrm{Si} / \mathrm{K}$ of about 22 (Figure 9); such a relationship is absent from

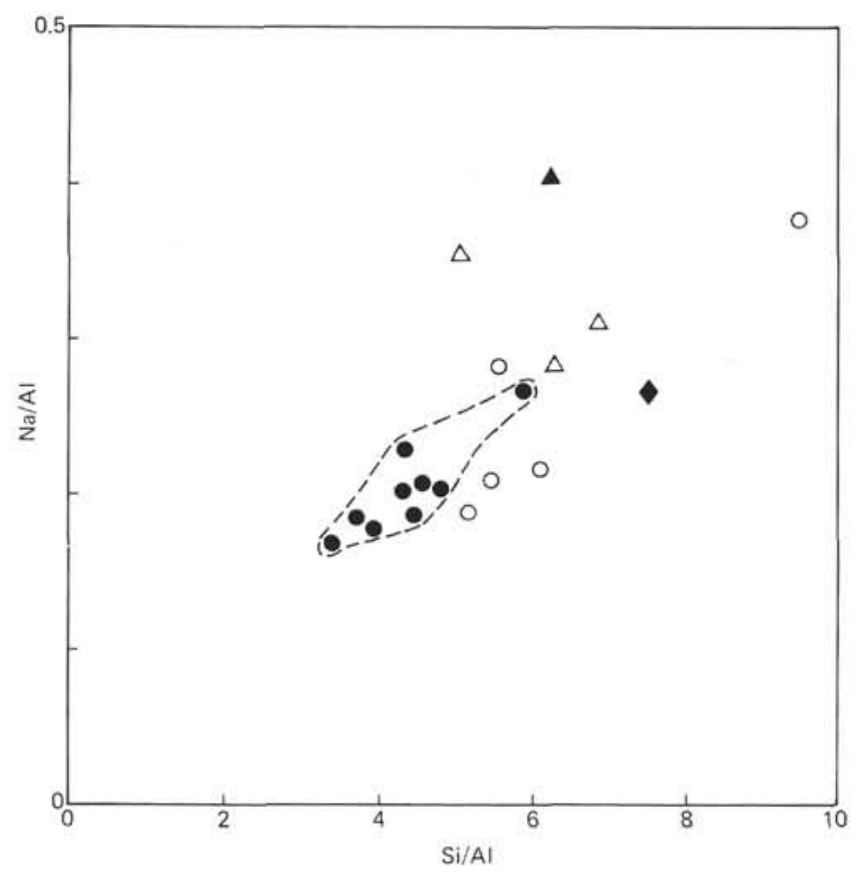

Figure 8. Diagram showing atomic ratios $\mathrm{Na} / \mathrm{Al}$ versus Si/Al for Site 420 sediments. Explanation as for Figure 7.

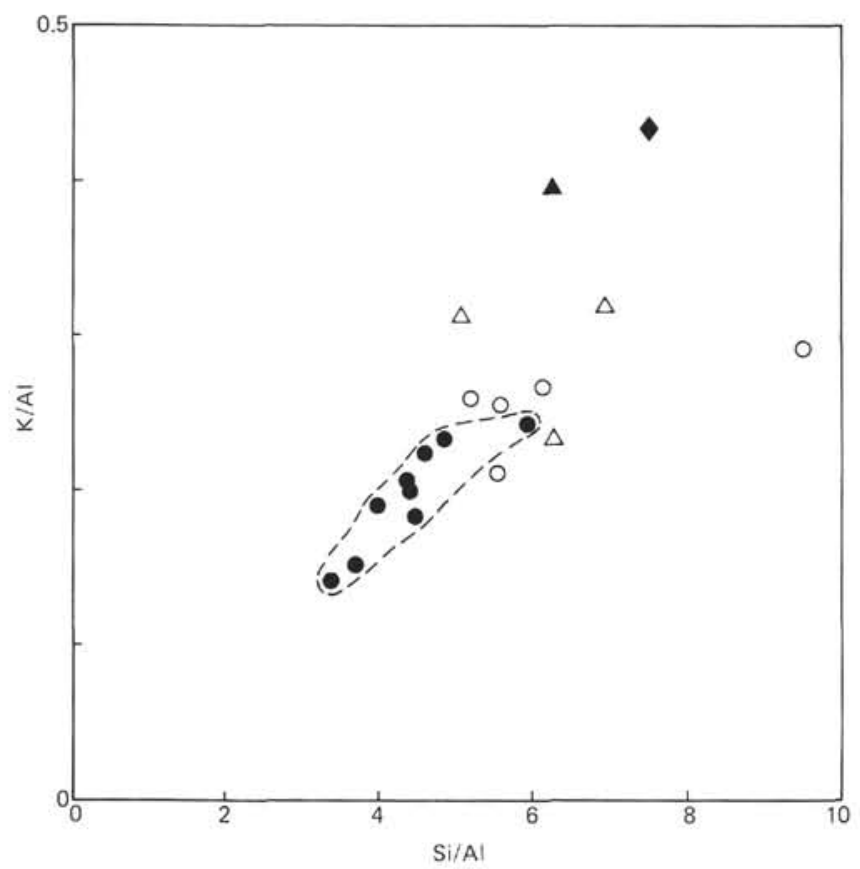

Figure 9. Diagram showing atomic ratios $K / A l$ versus Si/Al for sediments from Site 420. Explanation as for Figure 7.
DSDP Site 42 and otherwise rare in my experience, except in the presence of iron enrichment. I conclude, however, that the interrelationship among the elements $\mathrm{Si}, \mathrm{Mg}, \mathrm{Na}$, and $\mathrm{K}$ represents a manifestation of the more general case of enrichment on chemically active opal surfaces producing virtually stochiometric but amorphous surface "phases," as discussed in Donnelly and Merrill (1977). Also, the absence of a depletion in the pore-water $\mathrm{Mg}$ values at Site 420 is consistent with $\mathrm{Mg}$ saturation of the opal.

The deeper samples show different chemical relationships. Removing from consideration the forementioned volcanic samples mentioned, we find that the remaining samples show no coherence among $\mathrm{Si} / \mathrm{Al}$ on the one hand, and $\mathrm{Mg} / \mathrm{Al}, \mathrm{Na} / \mathrm{Al}$, or $\mathrm{K} / \mathrm{Al}$ on the other. Not shown is $\mathrm{Fe} / \mathrm{Al}$, which is also incoherent. However, there is a relationship among $(\mathrm{Fe}+\mathrm{Mg}) / \mathrm{Al}$ and $\mathrm{K} / \mathrm{Al}$ in these deeper samples which is well defined (Figure 10) and has the same ratio between $\mathrm{Fe}+\mathrm{Mg}$ and $\mathrm{K}$ as seen at Site 424. This coherence suggests that a similar smectite-mica phase may be forming, but that excess silica is variably present among the samples, which is seen as

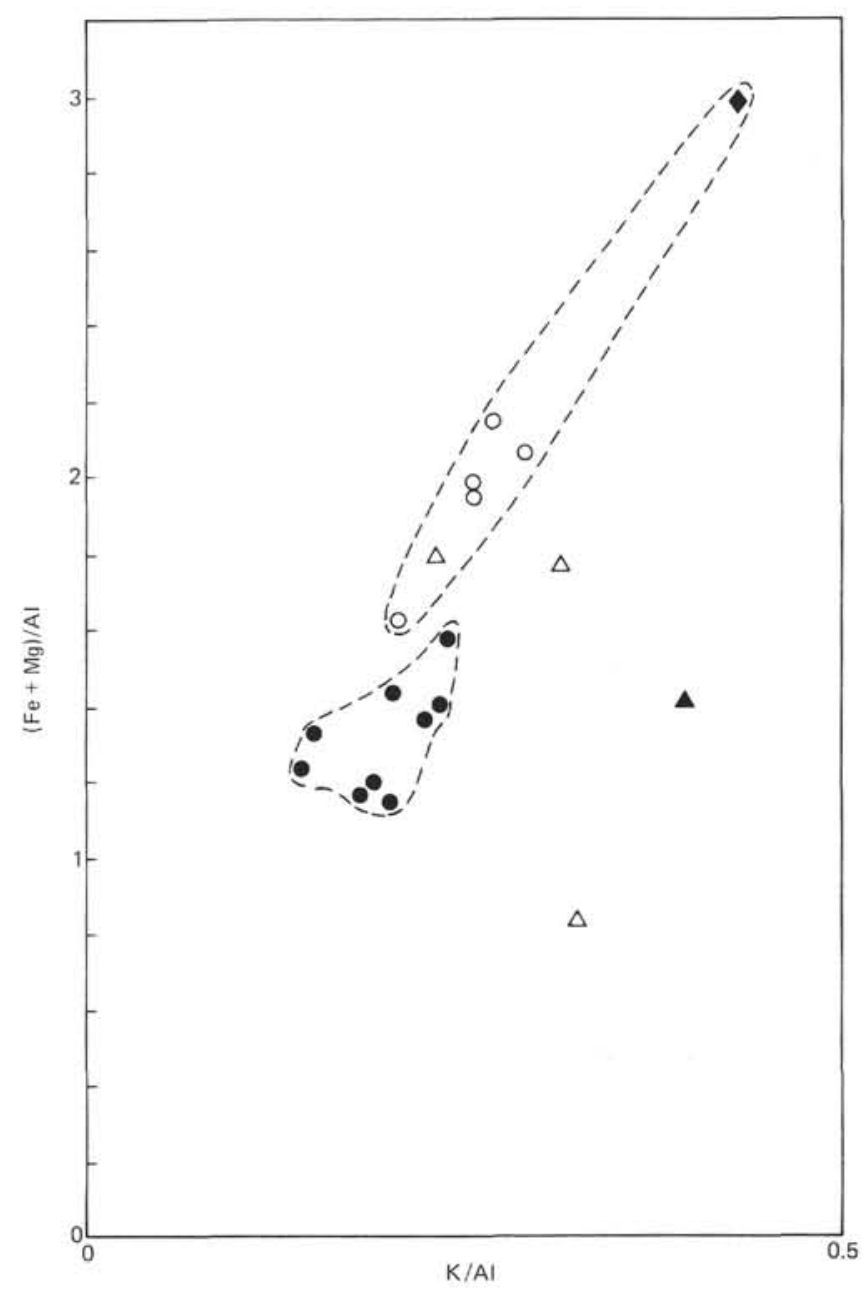

Figure 10. Diagram showing atomic ratio $(\mathrm{Fe}+\mathrm{Mg}) / \mathrm{Al}$ versus $\mathrm{K} / \mathrm{Al}$ for sediments from Site 420. Explanation as for Figure 7. 
radiolarian and diatomaceous opal. Smear slides show some pellets of birefringent material with a pale greenish color which may represent the same sort of phase present in this sediment, but its origin would probably be from a different segment of the spreadingridge axis.

\section{EXCESS ACCUMULATIONS OF OXIDES FROM EAST PACIFIC DRILLED SITES}

Table 3 shows the estimated amounts (in $\mathrm{g} / \mathrm{cm}^{2}$ ) of total excess accumulations of five oxides in several eastern Pacific drilled sites (values not listed if less than 20 per cent of the total element accumulation). The estimates were made by summing the accumulations downward at each site, using available biostratigraphy, shipboard determinations of density-porosity (GRAPE), and chemical analyses of the sediments. The basal enriched interval was identified by noting the highest level at which easily identifiable excessive iron was detected; often this was the shallowest sample, and I assume in these cases that excess element accumulation has not ceased. The terrigenous contributions (also volcanic, which are trivial at these sites) are subtracted by assuming a base atomic ratio of the elements with aluminum, which is considered not to be in excess. This base ratio was derived by a consideration of the occurrence of these elements in the world ocean, emphasizing hemipelagic occurrences (unpublished data), as well as using the observed ratios at the tops of some of the present sites which do not show iron enrichment. The upper parts of DSDP Sites 34 and 84 were also considered to reflect the compositions of typical eastern Pacific terrigenous debris. In any case, the terrigenous contributions are sufficiently low in all these occurrences that drastic changes in the base ratios result in only minor changes in the estimated excess accumulations. Thus, at DSDP Site 321, enrichment was found to occur over an interval of 33 m.y. If we change the base value of $\mathrm{Fe} / \mathrm{Al}$ from 0.30 to 0.275 , we would change the percentage of iron in that interval attributable to enrichment from 59 per cent to 63 per cent, and if we raise the base to 0.325 , the percentage becomes 56 . These shifts are high relative to the observed range of $\mathrm{Fe} / \mathrm{Al}$ in the sediments of the world ocean generally.

As Table 2 shows, iron and manganese excess accumulations are universal in the eastern Pacific Ocean. The period over which they are detectable is larger than might be expected from a simple petrographic inspection of the sediments; many of the enriched sediments (as at DSDP Site 42, for example) are very pale in color with no easily detectable iron-excessive phases. Especially surprising is the fact that closely juxtaposed sediments of greatly differing color (as at Site 420 ) have similar amounts of iron.

The excessive phosphorus found at these sites is not necessarily directly attributable to basal iron-manganese formation, although the association is well established (Boström et al., 1972; Donnelly and Wallace, 1976b; Froelich et al., 1977). My own data, largely unpublished, show that excessive phosphorus is also close- ly associated with biological productivity and the accumulation of purely biogenic materials. Because the eastern Pacific Ocean combines biological productivity with basal iron-manganese formation, the association of phosphorus with iron-manganese is necessarily somewhat ambiguous in this area.

The base value of $\mathrm{Mn} / \mathrm{Al}$ used here $(0.012 \mathrm{Mn} / \mathrm{Al}$ atomic ratio) is poorly determined, because of the variability of $\mathrm{Mn} / \mathrm{Al}$ ratios. It is a conservative ratio and is simply based on the pattern of observed occurrences of manganese in oceanic sediments for the world ocean. The scope of the present contribution makes further discussion of the complex behavior of manganese in enriched sediments inappropriate.

The occurrence of excessive magnesium in enriched sediments has been discussed elsewhere in various contexts (Donnelly and Merrill, 1977; Bischoff and Rosenbauer, 1977). There appear to be two patterns of occurrence: (1) as possibly amorphous coatings on biogenic opal, and (2) associated with iron-manganese enrichments. Site 424 sediments appear to belong to the second group, and Site 420 sediments largely to the first. Table 2 shows that most occurrences of significant magnesium enrichment are associated with high values of $\mathrm{Si} / \mathrm{Al}$, without specifying whether these are of biogenic origin (they would appear clearly to be so at Site 42 , as already discussed) or hydrothermal origin (hypothesized for Site 424). DSDP Sites 70 and 73 have smaller excess magnesium accumulations, but these are highly calcareous sediments and the determination of silicate magnesium values in such sediments is prone to large errors.

The occurrence of both excess potassium and iron is widespread but not universal in the eastern Pacific. There is no clear explanation for the variability of excess potassium accumulation seen in these estimates. The coherence between potassium on the one hand and the sum of iron and magnesium, on the other, is striking at Sites 424 and 420 and suggests that these elements are all associated in a single phase. This association is less convincing at other sites, and the complete explanation of the site of excess potassium and the mechanism of its incorporation in enriched sediments awaits further investigation.

\section{ACKNOWLEDGMENTS}

The chemical analyses were performed by Carol Terrana. This research is supported by National Science Foundation Grant OCE-74-13196. Discussions with Herman Roberson have been very helpful.

\section{REFERENCES}

Bischoff, J. L. and Rosenbauer, R. J., 1977. Recent metalliferous sediments in the North Pacific manganese nodule area. Earth Planet. Sci. Lett., v. 33, p. 379-388.

Boström, K. and Peterson, M. N. A., 1966. Precipitates from hydrothermal exhalations on the East Pacific Rise. Econ. Geol., v. 61, p. 1258-1265.

Boström, K., Joensuu, O., Valdes, S., and Riera, M., 1972. Geochemical history of South Atlantic Ocean since Late Cretaceous. Mar. Geol., v. 12, p. 85-121. 
Donnelly, T. W., in press. Chemistry of sediments of the western Atlantic: Site 417 compared with Sites 9, 105, 386, and 387. In Donnelly, T., Francheteau, J., Bryan, W., Robinson, P., Flower, M., Salisbury, M. et al., Initial Reports of the Deep Sea Drilling Project, v. 51, 52, 53, Part 2: Washington (U. S. Government Printing Office), p. 1515.

Donnelly, T. W. and Merrill, L., 1977. The scavenging of magnesium and other chemical species by biogenic opal in deep-sea sediments. Chem Geol., v. 19, p. 167-186.

Donnelly, T. W. and Wallace, J. L., 1976a. Major-element chemistry of the Tertiary rocks at Site 317 and the problem of the origin of the nonbiogenic fraction of pelagic sediments. In Schlanger, S. O., Jackson, E. D., et al., Initial
Reports of the Deep Sea Drilling Project, v. 33: Washir.gton (U. S. Government Printing Office), p. 557-562.

1976b. Major- and minor-element chemistry of Antarctic clay-rich sediments: Sites 322, 323, and 325, DSDP Leg 35. In Hollister, C. D., Craddock, C., et al., Initial Reports of the Deep Sea Drilling Project, v. 35: Washington (U. S. Government Printing Office) p. 427446.

Froelich, P. N., Bender, M. L., and Heath, G. R., 1977. Phosphorus accumulation rates in metalliferous sediments on the East Pacific Rise. Earth Planet. Sci. Lett., v. 34, p. 351-359. 